Villanueva Fernández, María. (Una) Caracterización del mobiliario moderno. Adolf Loos, Walter Gropius. Le Corbusier. Pamplona: Ediciones Universidad de Navarra, 2020, 210 págs. ISBN: 978-84-313-3473-4

\title{
LOOS, GROPIUS Y LE CORBUSIER: TEORÍAS DEL MUEBLE MODERNO
}

LOOS, GROPIUS, LE CORBUSIER: THEORIES OF THE MODERN FURNITURE

Ana María Fernández García*

El libro de María Villanueva es una auténtica delicia intelectual para cualquier lector interesado por el mobiliario moderno y por las gigantescas figuras de Loos, Gropius y Le Corbusier. Si ya por sí solos estos nombres son sugerentes, como pilares que fueron en la gestación del lenguaje moderno en la arquitectura, la caracterización de sus teorías sobre el mobiliario es un planteamiento original y un reto intelectual valiente y arriesgado. Podría parecer que no es posible escribir nada nuevo sobre los tres grandes creadores de la arquitectura moderna que fueron también prolíficos teóricos. Cabría pensar que estaba ya todo dicho y escrito después de tantos años y tantos reconocimientos. Precisamente el valor de este libro es el de descubrirnos que siempre caben nuevas lecturas en la investigación histórica, que no hay interpretaciones cerradas que fijen el punto final de cualquier estudio. El acervo histórico se enriquece con miradas renovadas, con metodologías audaces que suponen un avance en el conocimiento científico.

El libro de la doctora Villanueva sobresale en el panorama editorial por varios aspectos. El primero y, desde mi punto de vista, más importante es el minucioso estudio de las fuentes primarias, de los escritos teóricos de los tres arquitectos con el complemento de una completa bibliografía en diferentes lenguas. En segundo lugar, la autora ha sabido ofrecer una taxonomía de análisis que permite adentrarse en todos los aspectos que se quieren analizar por semejanza o por contraste. Bajo los epígrafes de Forma-Función, Artesanía-industria y Arquitectura-mobiliario se aglutinan los respectivos cuerpos teóricos de Loos, Gropius y Le Corbusier con subdivisiones en otras ideas derivadas, que en los márgenes se indican como palabras clave del discurso narrativo. Pero, sin duda, la gran aportación del libro es ofrecer una lectura especializada que rompe algunos tópicos admitidos por la historiografía y que revela aspectos inéditos de sus programas teóricos. En el caso de Loos el estudio se ha construido con más de ciento treinta escritos. Se repasa ese ideario donde el concepto de belleza está vinculado con lo práctico y donde el ornamento se tacha de algo primitivo y antieconómico, pero 
también se descubre que para el arquitecto cada mueble revela la historia de una familia y el conjunto decorativo cierra la historia de una vivienda. Se incide en el repudio del arquitecto como decorador o diseñador de muebles y en su defensa del mobiliario móvil, diseñado por ebanistas y heredero de la tradición, como signo verdaderamente moderno. Esa postura de Loos sobre los objetos modernos (prácticos, sinceros e individualizados) contrasta con la opinión de Gropius, defensor de la fusión entre arte y técnica y de la incorporación de cuestiones de carácter psicológico en el diseño. En el libro se explica con claridad el cambio de rumbo en las ideas del alemán y de la Bauhaus: del manifiesto original en defensa de la artesanía hasta que en 1923 se vio el interés de la producción industrial. Entonces la artesanía se convertiría en una herramienta formativa para poder llevar a abordar un diseño industrializado. También se trata en el texto del proyecto de Gropius de los tipos normalizados para los objetos de la vida cotidiana, los modelos experimentales, sintéticos y con una configuración que permitiese la fabricación de piezas industrializadas.

Más breve es el capítulo dedicado a Le Corbusier quizás porque sus disquisiciones teóricas sobre el mobiliario no son tan abundantes y se concentran en algunos capítulos de Vers une architecture, L'art decoratif d'aujourd'hui y Précisions sur un état présent de l'architecture et de l'urbanisme (publicados entre 1925 y 1936). En un planteamiento semejante a Gropius defenderá objetos-tipo que cubrirían necesidades-tipo y, como Loos, abundará en la crítica al ornamento. Muy interesante es la concepción de "muebles parásitos", aquellos que no sirven para nada y sólo colonizan el espacio, o la definición de una lista de muebles modernos y estandarizados, como el casillero (para guardar útiles de todo tipo), las mesas nido de varios tamaños y recogidas unas dentro de otras o las diferentes piezas de asiento, sillas, con diferentes formas y materiales en función a su utilidad: trabajo, descanso, etc., con la chaise longue, creada con Charlotte Perriand y Pierre Jeanneret, como una verdadera "máquina de descansar".

En definitiva, en las más de doscientas páginas de este libro se han estudiado los discursos teóricos sobre el mueble de los tres grandes arquitectos del Movimiento Moderno, debates que no son ajenos a la arquitectura, sino que sin intrínsecos a la renovación del espacio interior que defendían. Porque, como señalaba Le Corbusier, la renovación de la casa moderna se incardina con el análisis del mobiliario. Y la autora ha sabido leer interpretar, relacionar, categorizar y transmitir un inteligente retrato de esa renovación teórica promovida por ellos, convirtiendo este texto en un recurso indispensable para el estudio del mueble moderno.

Fecha de recepción: 3 de enero 2021

Fecha de revisión 12 de enero de 2021

Fecha de aceptación: 14 de enero de 202 